\title{
Interview
}

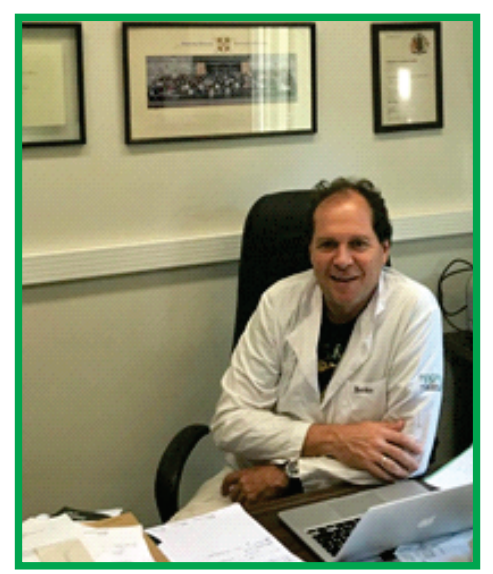

\section{Professor Norberto Peporine Lopes, who has a very prominent academic career, recently spoke with BrJAC}

\author{
Norberto Peporine Lopes \\ Full Professor at the Faculty of Pharmaceutical Sciences of \\ Ribeirão Preto, University of São Paulo, SP, BR \\ npelopes@fcfrp.usp.br
}

Professor Norberto Peporine Lopes is a pharmacist with a Master's degree in Pharmaceutical Sciences and a PhD in Chemistry from the University of São Paulo (USP). Currently, Norberto is a Full Professor of Organic Chemistry at the Faculty of Pharmaceutical Sciences of Ribeirão Preto (FCFRP-USP). He is also the coordinator of the Research Center for Natural and Synthetic Products and the Center for Mass Spectrometry of Organic Micromolecules (CEMMO). During his career, he has developed research abroad, in three long-term specializations at the Universities of Tübingem (Germany), Washington State (United States) and Bristol (United Kingdom). In 2000, he undertook postdoctoral training in mass spectrometry of natural products at the University of Cambridge (United Kingdom). From 2009 to date, he has held into a program of a Guest Professor in Mass Spectrometry at the Department of Food Chemistry of the University of Muenster (Germany).

Norberto is a full member of the Brazilian Academy of Sciences, in addition to the Brazilian Society of Pharmaceutical Sciences, the Brazilian Mass Spectrometry Society (BrMASS), the Brazilian Chemical Society (SBQ), the Brazilian Society of Pharmacognosy and is a Fellow of the Royal Chemical Society. Among these societies, he holds the position of President of the Brazilian Chemical Society and is a member of the BrMASS Board.

He has published more than 350 scientific articles and received eight awards, in particular, the BrMASS and Fernando Galembeck's SBQ Medals. When he received the BrMASS medal, he was surprised to be recognized by the congress: "I was surprised, I was very happy of course, but I was surprised because when we created this honor in society, it had as its main focus to honor the pioneering researchers," Norberto told the Web portal "Visão Ciência".

The research interests of the Professor are centered on natural product chemistry and mass spectrometry in both basic chemical aspects (gas phase reaction mechanism studies) and their biological and ecological importance. More recently, he has dedicated himself to contributing to the understanding of the phase one metabolism of natural xenobiotics. Nowadays, he is the coordinator of a thematic FAPESP project on the subject and has worked with passion in the field of chemical ecology since the beginning of his career. His laboratory, therefore, has special interest in all aspects of the discovery of new natural products and has a strong track record for innovation. Five spins off were born from his group, with most of them being created by former postdoctoral researchers.

When was your first contact with chemistry? Did you have any influencer, for example, a teacher?

Since childhood I have been very curious about issues related to nature. Over the years, I joined my father on his field trips and became familiarized in the phytochemical area, since my father and uncle were both USP professors. My contact with botanists and chemists influenced me significantly and I can say that I grew up breathing in natural product chemistry. 


\section{When did you decide to begin a career in chemistry? What motivated you? How was the beginning of your career?}

By the mid-1980s, the issues surrounding genetics were boiling and the growing fascination with this area made me choose a subject where I could get in touch with the different focuses of biology and chemistry. Thus, in 1986, I joined the Faculty of Pharmaceutical Sciences of Ribeirão Preto (USP), where I took internships and participated in scientific initiation programs in biological fields. After working as a FAPESP fellow in a project on the regulatory mechanisms of glucose metabolism, the opportunity arose to work at the University of Tübingen in Germany in a project in plant cell culture of the Digitalis species. Despite my intimate contact with plants, as a result of the phytochemical work carried out by my father and uncle all my life, I had never thought of working with them, but the fascination was so great that I decided to carry out my work in the German laboratory with phytochemistry of these cells. Since that point, I returned to my family origins and have never stopped working on natural product chemistry and related

By the mid-1980s, the issues surrounding genetics were boiling and the growing fascination with this area made me choose

a subject where I could get in touch with the different focuses of biology and chemistry. topics.

What are your lines of research? What jobs are you currently working on? Have you published many scientific papers? Would you highlight any?

We are currently working with the application of mass spectrometry in the analysis of natural products. In our group, we investigate the chemistry of animals, plants and microorganisms, with the aim of understanding secondary metabolite functions. In these protocols, we apply mass spectrometry as the main tool for the metabolomics and for the imaging studies. With regard to scientific publications, we have been able to significantly increase both quantitative and qualitative production in the last decade, which I believe is the current challenge of Brazilian Science. In this sense, I believe that for the metric indicators of the agencies, the articles that we publish in journals such as Nature Biotechnology, Chemical Society Reviews, PNAS, Nature Ecology and Evolution would be the most outstanding. However, I think the two most important contributions were the compilation of the fragmentation reactions in ESI-MS/MS systems and the characterization of caramboxin. The work published in the Natural Products Report organized and systematized these reactions in a pioneering way and today it is used as courseware of structural determination applying mass spectrometry, so it has had a significant impact on the training of students, something we strongly consider. The second was a cover work for Angewandte Chemie, in which the strongest point is the social impact. The letters and emails my co-workers and I have received about lives that have been saved based on this article cannot be described here.

How do you keep informed about the progress of chemistry research? What is your opinion regarding the current progress of research in chemistry in Brazil? What are the latest advances and challenges in scientific research in Brazil?

My position on the SBQ board allows me to follow what is happening with Chemistry, both at national and international levels. One point that has attracted our attention is the gradual increase in the scientific production of chemistry in Brazil and mainly the increase in the number of articles signed by Brazilians in the main periodicals of the area. I think the biggest challenge today is to convert scientific data into innovation in the productive sector, to become more active in the development of new products. It is true that the number of academic spins off has grown significantly and the chemistry is also contributing in this

I think that one of the greatest social impacts of current analytical chemistry is the doctorate of Dr. Livia Eberlin with Prof. Cooks. Bringing the mass equipment into the surgical room in the hospitals will strongly impact the mass spectrometry field. scenario, but I believe that with the publication of the "Legal Framework of Science, Technology and Innovation" (Law no 13.243 / 2016, published on 08/02/ 2018), we will have an even greater participation. 


\section{Interview}

In your opinion, what have been the most important achievements in the world of analytic research recently? What were the landmarks?

We could discuss different advances, but drawing more focus to the Brazilians, I think that one of the greatest social impacts of current analytical chemistry is the doctorate of Dr. Livia Eberlin with Prof. Cooks. Bringing the mass equipment into the surgical room in the hospitals will strongly impact the mass spectrometry field. Another great advance has been the ability to generate an ever-increasing collection of analytical data, and with the new computational tools, we start working with metadata. For nearly 20 years, computational chemistry and biology have already been recognized as independent research fields, merging a set of computational, statistical, mathematical and other fields of research involved in data processing that are generated by analytical chemists.

According to the director of the Stanford University Biomedical Computing Training Program in Palo Alto, California, Prof. Russ Altman, the market with lucrative salaries is absorbing metadata scientists as they graduate. In an article written for the journal Science in the section dedicated to professional careers, Prof. Russ Altman points out that in traditional training, chemists and biopharmacologists are trained for smallscale analysis and that the new challenge will be to extend the logic of scale, which was a major step forward for the decade.

There are several scientific meetings on chemistry in Brazil and around the world. To you, how important are these meetings for the area? How do you see the development of national scientific chemistry meetings in Brazil?

Conferences are important events for professional updating and also for maintaining networks. As in any field, networking is fundamental to broaden collaborations and discuss new ideas. However, we can nowadays find a large number of events with commercial purposes all over the world. It is important to analyze carefully, as it has become a good business model that can also be seen with the scientific journals, aiming only for profit.

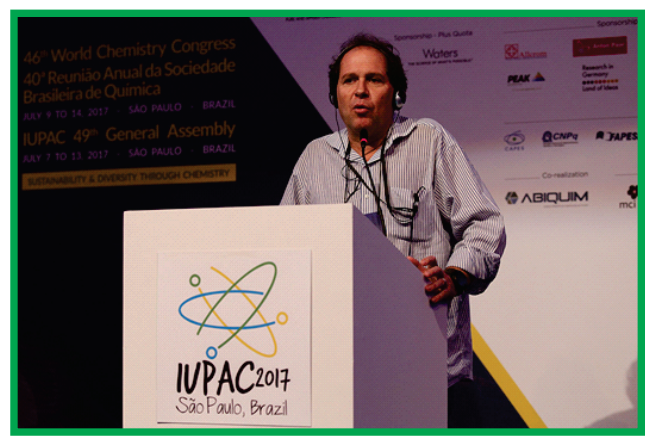

Prof. Norberto Peporine Lopes presenting a lecture at IUPAC World Congress - 2017

In Brazil, we have a certain degree of spraying, with many very specialized congresses for specific subjects. As a result, we can see a decrease in the participation of researchers in larger meetings and it can become a problem. In the US, ACS meetings are one of the largest events in the American scientific community. This forum discusses policies, strategies and the main scientific advances of all sub-areas of chemistry. This gives strength to this community and helps maintain sovereignty in internal affairs over chemistry. In Brazil, it seems that we are worrying much more about the specialization and it may have an impact on the future. Moreover, young Brazilian researchers are not absorbing the fundamental concept of participating in a scientific society, thinking only of the meeting itself. In my opinion, this is another aggravating point.

You have already received awards. What is it like to receive this kind of recognition? What is the importance of these awards in the development of science and new technologies?

The vast majority of us have a degree of vanity. Therefore, receiving a prize is always a great joy, but I believe it is very important to analyze the honor in an easy way. What makes us productive is to believe that every day we have something new to learn and grow. Thus, in my opinion the premiums are always important, but they cannot be met with an increased dose of self-confidence. Recognizing, honoring 
and rewarding people is a healthy act, especially when performed in life. As I mentioned before, every form of stimulation can advance us further and generate new knowledge and technologies.

For you, what is the importance of the support of the research funding agencies (Coordination for the Improvement of Higher Education Personnel - CAPES, São Paulo Research FoundationFAPESP and so on) for the scientific development of Brazil?

By definition, the development agency is the institution with the main objective of financing capital and costing for projects foreseen in scientific and innovation development programs. Therefore, without the existence of development agencies there would be no research in Brazil. In the last decade, the agencies have started to act more actively in innovation and today there are several companies of national capital that were born in the universities and only reached the market by the initial incentive of these agencies. Another important point is that agencies, such as CAPES, act in the evaluation system. I am not here to state whether the evaluation model is correct or not, but just to reinforce that any program or system needs to be evaluated to evolve. Without evaluation, we have the characteristic of accommodation that is bad for the development of science and technology.

How is a career in the field of analytical chemistry? What advice would you give to a newcomer in this area?

Doing just what is expected of the person will usually produce a good technician but will hardly result in a professional that will make a difference in the market.
My parents taught me to always look for the best. Doing just what is expected of the person will usually produce a good technician but will hardly result in a professional that will make a difference in the market. My main advice is to analyze your vocation well and make sure that you really enjoy research and want to take all the risks that this option will bring. Taken that decision, dedicate yourself as much as you can, especially in reading and studying, something that we are reducing day by day by the current lifestyle.

With the current scenario, how is the labor market in analytical chemistry in Brazil? What differs from working abroad?

Brazil is going through a very complicated economic and social moment. Previous models of postgraduate studies with a view to teaching careers are well established and there should be no further expansion in the coming years. Therefore, graduate programs in analytical chemistry should shift the focus to the absorption of this highly qualified human material by the productive sector. In our group, we have several experiences of alumni today occupying important positions in pharmaceutical companies and some have been brave and set out to create their own business models, something that I view with good eyes. Abroad, the productive sector absorbs a greater quantity of analytical chemists and with better salaries. I believe this is the big difference, because with a greater supply in the productive sector, the impoundment of positions in academia diminishes. 